\title{
Tissue Engineering Scaffolds for the Regeneration of Craniofacial Bone
}

Wailan D. Chan, MESC; Hiran Perinpanayagam, DDS, PhD;

Harvey A. Goldberg, PhD; Graeme K. Hunter, PhD; S. Jeffrey Dixon, DDS, PhD;

Gildo C. Santos Jr., DDS, PhD; Amin S. Rizkalla, PhD, PEng

\section{Contact Author}

Dr. Rizkalla

Email: arizkalla@

eng.uwo.ca

\section{ABSTRACT}

Current strategies for skeletal regeneration involve the use of autogenous and allogenic bone grafts that may not always be available or safe to use. One alternative is to develop materials for use as scaffolds for the tissue engineering of bone. We created architecturally nanofibrous scaffolds using the electrospinning technique. These calcium phosphate-based materials are porous, have a large surface-area-to-volume ratio and can be used to deliver drugs, biologics or cells for tissue engineering applications. Bone-matrix proteins were also conjugated to the surface of a polymer network of polycaprolactone and poly(2-hydroxyethyl methacrylate) to create a material with enhanced cellular responses. This biomimetic strategy resulted in favourable cell-surface interactions that will likely enhance bone-matrix synthesis and regeneration. These collective advancements enable the development of innovative scaffolds for applications in tissue engineering and bone regeneration.

R ecent advancements in implant dentistry, along with increased patient demands for implant-supported prostheses, have resulted in a heightened need for bone augmentation that goes beyond traditional periodontal regeneration. For instance, decreased ridge width because of resorption from tooth loss may preclude the placement of endosseous implants. ${ }^{1}$ Bone augmentation may also be necessary for the treatment of edentulous patients if they lack the appropriate bone volume that would ensure the long-term stability of implants. ${ }^{2}$ In such cases, materials that permit new bone formation (osteoconductive) or promote new bone formation (osteoinductive) are used (Fig. 1). The use of autogenous bone grafts is the standard against which other bone-graft substitutes are compared, but the availability of autogenous bone grafts is often limited. ${ }^{3}$ Allogenic bone grafts are a good alternative, but carry risks of immunoreactivity and disease transmission. Synthetic bone grafts are an important substitute, and improvement of their effectiveness is an ongoing research endeavour. In this paper, we describe 2 promising new tissue engineering approaches for enhancing bone regeneration that use matrixlike scaffolds to restore bone architecture and functionality. 


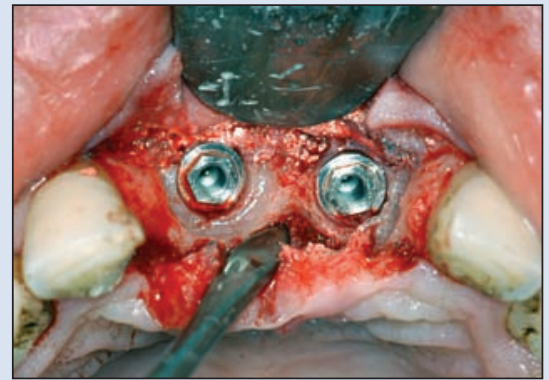

Figure 1: Limitations of existing strategies for bone regeneration. This patient had a fracture in tooth 21 that extended deep into the root. The tooth had been restored with a large post and core, and tooth 11 was extracted 8 years before. The treatment consisted of extracting tooth 21 and filling the tooth socket with an allograft to preserve the existing architecture and induce new bone formation. In addition, a combination of autograft and allograft materials was used to reconstruct the site for tooth 11. After 4 months of healing, implants were placed using a 2-stage technique. When the surgical site was reopened 4 months after the implant was placed (8 months after grafting), considerable residual material was seen.
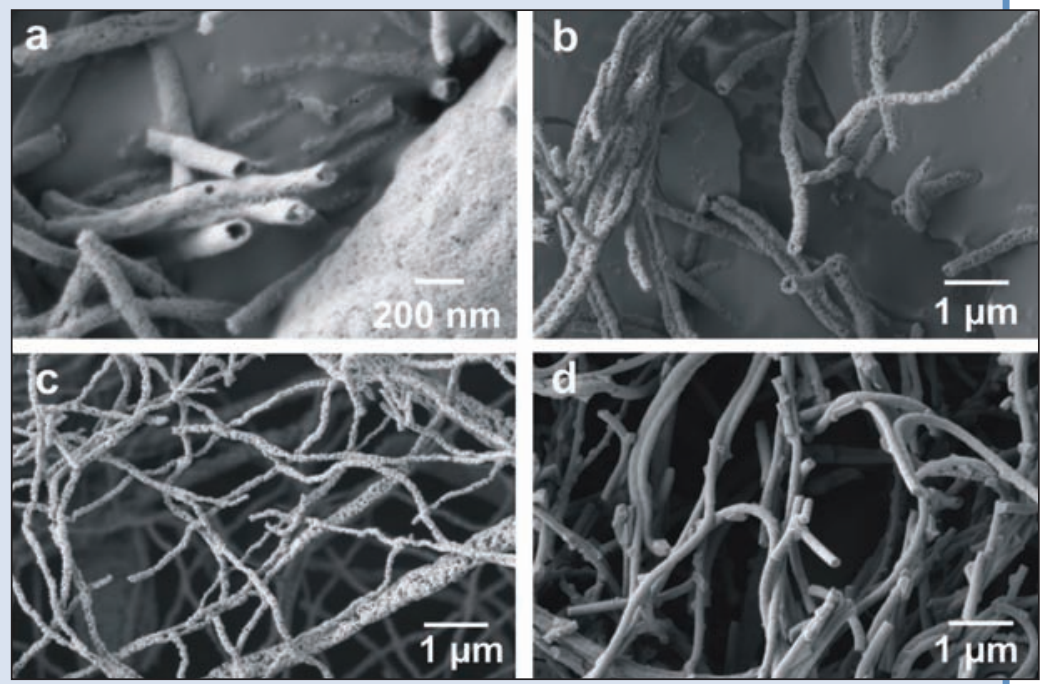

Figure 2: Calcium phosphate nanofibres observed by scanning electron microscopy. Calcium phosphate nanofibres with various morphologies and architecture were produced by changing the conditions of synthesis: (a) tubular fibres; (b and c) porous fibres, and (d) solid fibres.

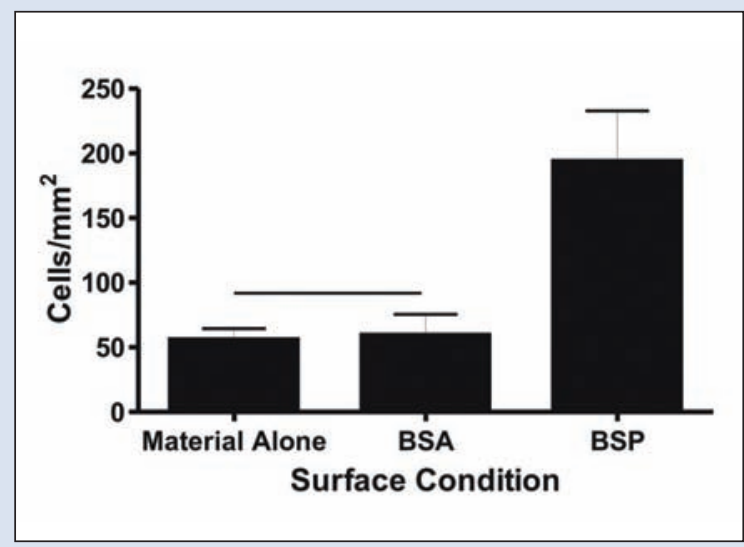

Figure 3: A graph comparing the number of cells attached to untreated polymer surfaces with the number attached to surfaces treated with bovine serum albumin (BSA, inactive control) or bone sialoprotein (BSP, active). Mouse preosteoblasts (MC3T3-E1 cells) were incubated for $2 \mathrm{~h}$ on the surfaces of polycaprolactone/poly(2-hydroxyethyl methacrylate) polymer, or polymer conjugated with BSA or BSP. Surfaces were washed and the attached cells were observed with confocal microscopy. The number of attached cells was expressed per unit area. BSP-conjugated surfaces supported significantly greater cell attachment than untreated or BSAconjugated surfaces $(p<0.05)$. Horizontal line indicates groups that are not significantly different.

\section{Biomaterial Scaffolds for Tissue Engineering of Bone}

During tissue engineering, cells and growth factors are combined with a porous biodegradable scaffold to repair and regenerate tissue. The scaffold acts as a temporary matrix while the cells secrete the extracellular matrix (ECM) that is required for tissue regeneration. Two routes have been proposed for bone regeneration by tissue engineering: 1) the use of scaffolding materials that induce the formation of bone following the ingrowth of cells from the surrounding tissues, and 2) the use of scaffolds as carriers for seeded autogenous osteogenic cells that are cultured in bioreactors and subsequently reimplanted into the patient. ${ }^{4}$ The first modality can be thought of as in vivo tissue engineering, since the patient's body is used as the bioreactor to produce bone. In this approach, scaffolds used to induce bone formation from surrounding tissues include calcium phosphatebased materials. Given the apatite-like composition of bone mineral, calcium phosphate materials such as hydroxyapatite and tricalcium phosphate have been developed for use as scaffolds. ${ }^{5-10}$ In the second modality, osteogenic cells are removed from the patient and cultured with the scaffold materials in vitro. After an appropriate cultivation time, the cell-matrix construct is implanted into the patient, where it guides the regenera- 

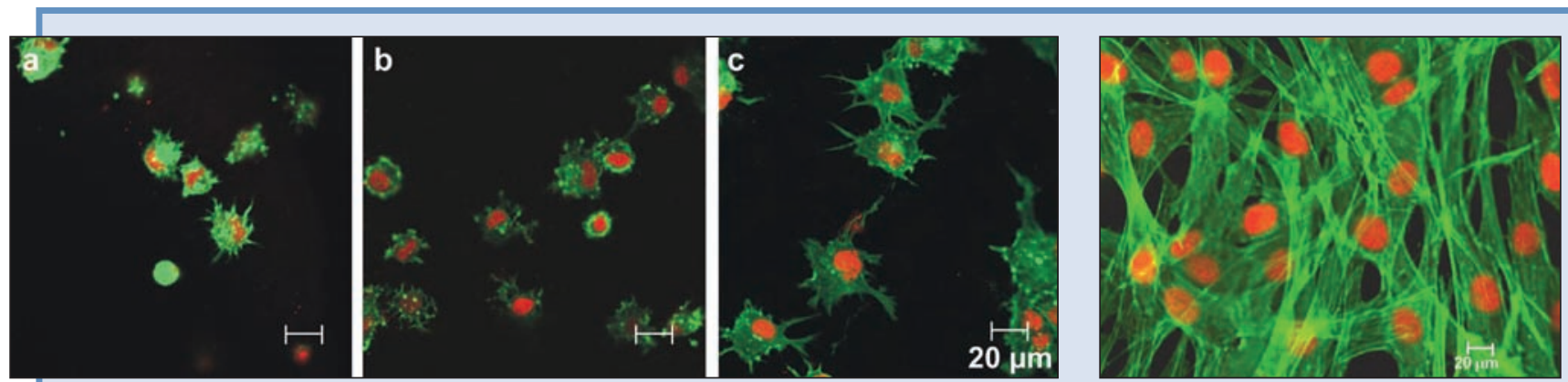

Figure 4: Osteoblast spreading on bone matrix protein-modified polymers. Micrographs show cell morphology on polycaprolactone/poly(2-hydroxyethyl methacrylate) surfaces after $2 \mathrm{~h}$. MC3T3-E1 cells were seeded onto the following surfaces: (a) unmodified, (b) bovine-serum-albumin-conjugated, and (c) bone-sialoprotein (BSP)-conjugated. Cells were observed with confocal microscopy; nuclei were stained with propidium iodide (red) and filamentous actin with Alexa-Fluor 488 phalloidin (green). Cells were more spread on BSP-conjugated surfaces than on control surfaces.

Figure 5: Micrograph shows cell morphology after $24 \mathrm{~h}$ incubation on polycaprolactone/poly(2-hydroxyethyl methacrylate) conjugated with bone sialoprotein. Cells were observed with confocal microscopy; nuclei were stained with propidium iodide (red) and filamentous actin with Alexa-Fluor 488 phalloidin (green). tion of bone. Polymer scaffolds can be fabricated into the required anatomical shapes. Proof-of-principle studies have been done on tooth-alveolar bone constructs ${ }^{11}$ and mandibular reconstruction. ${ }^{12,13}$ Research in scaffold design is an important facet of tissue engineering.

Native ECM is a hierarchically organized nanocomposite. Understanding tissue organization from the molecular to the macroscopic level will likely guide the rational design of synthetic ECM substitutes. ${ }^{14}$ Tissueengineering scaffolds should recapitulate this hierarchical organization. With recent advances in nanotechnology, insight into nanoscale organization is accumulating, and nanofibrous and nanocomposite scaffolds that attempt to mimic the nanoscale morphological features of natural ECM are being developed. ${ }^{14-16}$

A recent development in calcium phosphate-based scaffolds has been the fabrication of nanofibres. ${ }^{17}$ Nanometre-sized fibres have a large surface-area-tovolume ratio and can be processed so that they have high porosity. These features are advantageous because they permit the delivery of drugs or growth-factors, and allow cell migration and nutrient diffusion. Architecturally elaborate scaffolds of calcium phosphate nanofibres have now been created in our laboratory (Fig. 2). Our initial studies ${ }^{18}$ have shown that porous, tubular or solid fibres can be preferentially generated under specified conditions, with diameters ranging from 100 to $200 \mathrm{~nm}$. Custom fabrication of these nanostructures with a combination of electrospinning and calcination of sol-gel precursors and polymer solutions will enable the synthesis of nanoscaffolds that are finely attuned to their specific biomedical application.

Effective tissue-engineering scaffolds need to support the attachment and proliferation of cells, and the synthesis of new matrix. Improvement in the capacity of these materials to promote such cell-surface interactions will lead to advancements in their clinical application. Modification of scaffold surfaces is commonly used to control cell interactions with the biomaterial interface. For instance, a biomimetic approach to improving cell attachment has been the modification of biomaterials with the arginine-glycine-aspartic-acid (RGD)-peptide sequence. ${ }^{19}$ Proteins with these sequences bind to cellsurface receptors, facilitating the attachment of cells to substrata. Bone sialoprotein is an RGD-containing protein that is abundant in mineralized tissues at sites of de novo bone formation and in new mineral foci. ${ }^{20}$ Bone sialoprotein is also able to nucleate hydroxyapatite crystals in vitro. ${ }^{21}$ These findings suggest that bone sialoprotein mediates early mineral formation. Additionally, in a rat model of pulp-dentin defects, the use of bone sialoprotein resulted in more rapid repair, ${ }^{22}$ suggesting that bone sialoprotein could be used in a therapeutic device to repair bony defects through an osteoinductive process. Therefore, it may be advantageous to exploit the functions of bone sialoprotein in skeletal tissue engineering. We have developed polycaprolactone/poly(2-hydroxyethyl methacrylate) (PCL/pHEMA) polymer networks that are surface-modified with full-length bone sialoprotein. ${ }^{23}$ Quantitative cell-attachment assays revealed enhanced osteoblastic cell attachment on bone sialoprotein-modified surfaces compared with that of control surfaces (unmodified or albumin conjugated) (Fig. 3). Cells were also more extensively spread on bone sialoproteinmodified surfaces (Figs. 4 and 5). The enhanced cell attachment and spreading that we have found on bone sialoprotein-conjugated polymer scaffold surfaces is likely mediated through cell-surface receptors for RGD 
sequences. These receptors are also important for cell differentiation. ${ }^{24,25}$ Therefore, these enhanced cell-surface interactions found on bone sialoprotein-modified surfaces will likely assist other desirable events. Enhancement of cell proliferation, differentiation, matrix synthesis and survival will undoubtedly facilitate the regeneration of bone.

\section{Summary of Research and Future Directions}

Synthetic biomaterials are suitable scaffolds for tissue-engineering approaches to bone regeneration. These porous scaffolds provide a matrix-like structure for osteoblast attachment, migration, proliferation, differentiation and ECM deposition. Through our ongoing research, we have fabricated 2 novel scaffolds for this purpose. We have used advanced electrospinning techniques to generate calcium phosphate nanofibres within architecturally elaborate lattice-like structures that are likely to have widespread applications in tissue engineering. In addition, we have conjugated bone sialoprotein onto PCL/pHEMA polymer surfaces to improve cell attachment and spreading. These cellular events on ECM substrata are important modulators of subsequent signalling pathways that determine cell fate and function. Ongoing research focuses on characterizing downstream events, including cell proliferation and differentiation, and bonematrix synthesis. These surface-modified scaffolds constitute a biomimetic approach to tissue engineering and bone regeneration. $\Rightarrow$

\section{THE AUTHORS}

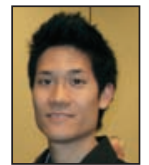

Mr. Chan is a dental student at the Schulich School of Medicine \& Dentistry, The University of Western Ontario, London, Ontario.

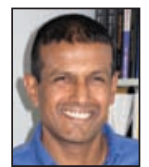

Dr. Perinpanayagam is associate professor in the division of restorative dentistry, Schulich School of Medicine \& Dentistry, The University of Western Ontario, London, Ontario.

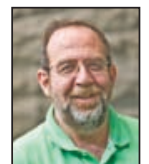

Dr. Goldberg is professor and chair of the division of oral biology, and member of the CIHR Group in Skeletal Development and Remodelling at the Schulich School of Medicine \& Dentistry, The University of Western Ontario, London, Ontario.

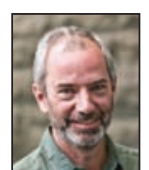

Dr. Hunter is professor of oral biology and of biochemistry, and member of the CIHR Group in Skeletal Development and Remodelling at the Schulich School of Medicine \& Dentistry, The University of Western Ontario, London, Ontario.

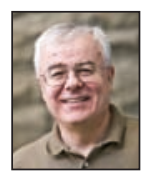

Dr. Dixon is professor of physiology and pharmacology and of oral biology, director of the CIHR Group in Skeletal Development and Remodelling, and assistant director of research in dentistry at the Schulich School of Medicine \& Dentistry, The University of Western Ontario, London, Ontario.

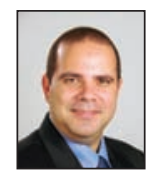

Dr. Santos is assistant professor in the division of restorative dentistry, Schulich School of Medicine \& Dentistry, The University of Western Ontario, London, Ontario.

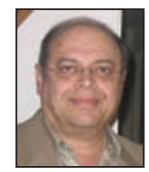

Dr. Rizkalla is associate professor in the department of chemical and biochemical engineering, faculty of engineering, and chair of the division of biomaterials science, Schulich School of Medicine \& Dentistry, The University of Western Ontario, London, Ontario.

Acknowledgements: The original research described here was supported by NSERC and CIHR.

Correspondence to: Dr. Amin S. Rizkalla, Division of biomaterials science, Schulich School of Medicine \& Dentistry, The University of Western Ontario, London, ON N6A 5C1.

The authors have no declared financial interests.

This article has been peer reviewed.

\section{References}

1. Geurs NC, Korostoff JM, Vassilopoulos PJ, Kang TH, Jeffcoat M, Kellar R, and other. Clinical and histological assessment of lateral alveolar ridge augmentation using a synthetic long-term bioabsorbable membrane and an allograft. J Periodontol 2008; 79(7):1133-40.

2. Aghaloo TL, Moy PK. Which hard tissue augmentation techniques are the most successful in furnishing bony support for implant placement? Int J Oral Maxillofac Implants 2007; 22 Suppl:49-70.

3. Finkemeier CG. Bone-grafting and bone-graft substitutes. J Bone Joint Surg Am 2002; 84-A(3):454-64.

4. Burg KJ, Porter S, Kellam JF. Biomaterial developments for bone tissue engineering. Biomaterials 2000; 21(23):2347-59.

5. Bucholz RW. Nonallograft osteoconductive bone graft substitutes. Clin Orthop Relat Res 2002; (395):44-52.

6. Irwin RB, Bernhard M, Biddinger A. Coralline hydroxyapatite as bone substitute in orthopedic oncology. Am J Orthop 2001; 30(7):544-50.

7. Bojescul JA, Polly DW Jr, Kuklo TR, Allen TW, Wieand KE. Backfill for iliaccrest donor sites: a prospective, randomized study of coralline hydroxyapatite. Am J Orthop 2005; 34(8):377-82.

8. Resnick DK. Vitoss bone substitute. Neurosurgery 2002; 50(5):1162-4.

9. Anker CJ, Holdridge SP, Baird B, Cohen H, Damron TA. Ultraporous betatricalcium phosphate is well incorporated in small cavitary defects. Clin Orthop Relat Res 2005; (434):251-7.

10. Yuan H, De Bruijn JD, Li Y, Feng J, Yang Z, De Groot K, and other. Bone formation induced by calcium phosphate ceramics in soft tissue of dogs: a comparative study between porous alpha-TCP and beta-TCP. J Mater Sci Mater Med 2001; 12(1):7-13

11. Young CS, Abukawa $H$, Asrican R, Ravens M, Troulis MJ, Kaban LB, and others. Tissue-engineered hybrid tooth and bone. Tissue Eng 2005; 11(9-10):1599-610.

12. Abukawa H, Terai $H$, Hannouche D, Vacanti JP, Kaban LB, Troulis MJ. Formation of a mandibular condyle in vitro by tissue engineering. J Oral Maxillofac Surg 2003; 61(1):94-100.

13. Warnke PH, Springer IN, Wiltfang J, Acil $Y$, Eufinger $H$, Wehmoller $M$, and others. Growth and transplantation of a custom vascularised bone graft in a man. Lancet 2004; 364(9436):766-70.

14. Goldberg M, Laner R, Jia X. Nanostructured materials for applications in drug delivery and tissue engineering. J Biomater Sci Polym Ed 2007; 18(3):241-68.

15. Murugan R, Ramakrishna S. Nano-featured scaffolds for tissue engineering: a review of spinning methodologies. Tissue Eng 2006; 12(3):435-47.

16. Smith LA, Ma PX. Nano-fibrous scaffolds for tissue engineering. Colloids Surf B Biointerfaces 2004; 39(3):125-31.

17. Kim HW, Kim HE. Nanofiber generation of hydroxyapatite and fluorhydroxyapatite bioceramics. J Biomed Mater Res B Appl Biomater 2006; $77(2): 323-8$ 
18. Chan WC, Rizkalla AS. Preparation of calcium phosphate fibers by electrospinning technique. J Dent Res 2008; 87(Special Issue B). Abstract no. 1488. Available: http://iadr.confex.com/iadr/2008Toronto/techprogram/ abstract_104412.htm.

19. Hersel U, Dahmen C, Kessler H. RGD modified polymers: biomaterials for stimulated cell adhesion and beyond. Biomaterials 2003; 24(24):4385-415.

20. Chen JK, Shapiro HS, Wrana JL, Reimers S, Heersche JN, Sodek J. Localization of bone sialoprotein (BSP) expression to sites of mineralized tissue formation in fetal rat tissues by in situ hybridization. Matrix 1991; 11(2):133-43.

21. Hunter GK, Goldberg HA. Nucleation of hydroxyapatite by bone sialoprotein. Proc Natl Acad Sci U S A 1993; 90(18):8562-5.

22. Goldberg M, Six N, Decup F, Buch D, Soheili Majd E, Lasfargues JJ, and others. Application of bioactive molecules in pulp-capping situations. Adv Dent Res 2001; 15(1):91-5.

23. Chan WC, Goldberg HA, Hunter GK, Rizkalla AS. Biomimetic materials for skeletal repair. Abstract presented at the 25th Annual Meeting of the Canadian Biomaterials Society, Calgary, Alberta, 2006.

24. Van der Flier A, Sonnenberg A. Function and interactions of integrins. Cell Tissue Res 2001; 305(3):285-98.

25. Ruoslahti E. RGD and other recognition sequences for integrins. Annu Rev Cell Dev Biol 1996; 12:697-715. 